\title{
INTEGRATION OF COMMUNITY SETUP IN PHARMACEUTICAL CARE: CURRENT CHALLENGES, PERCEPTION, FACTS AND OPPORTUNITIES IN PAKISTAN
}

\author{
HUMA ALI ${ }^{1 * *}$, FARYA ZAFAR ${ }^{2}$, SHAZIA ALAM ${ }^{3}$, NEELAM MALLICK ${ }^{3}$, HINA HASNAIN $^{3}$, GHAZALA RAZA NAQVI ${ }^{4}$, \\ ZEB-UN-NISA ${ }^{3}$, ANUM TARIQ ${ }^{3}$, ASLAM SHAH ${ }^{3}$
}

1Faculty of Pharmacy, Jinnah Sindh Medical University, Karachi, Pakistan, ${ }^{2}$ Faculty of Pharmacy, University, Karachi, Karachi, Pakistan, ${ }^{3}$ Faculty of Pharmacy, Ziauddin University, Karachi, Pakistan, ${ }^{4}$ Faculty of Pharmacy, Federal Urdu University, Karachi, Pakistan Email: humaali80@live.com

Received: 31 May 2016 Revised and Accepted: 12 Aug 2016

\begin{abstract}
Objective: A qualitative, cross-sectional survey-based study was conducted to evaluate the integration of community setup in pharmaceutical care with respect to current challenges, awareness/perception of individuals from various walks of life, related facts and opportunities which are contextual to local settings in Karachi, Pakistan.

Methods: This cross-sectional, a qualitative study, was conducted between May-November 2015. A questionnaire was designed using 15 close ended and 5 open-ended questions. And validated using correlation of spearman coefficient and Cronbach's $\alpha$ value $(\alpha=0.916$ and $p=0.941)$. Local residents, pharmacist, medical practitioners, and pharmacy technicians were selected as study participants. Informed consents of all respondents were obtained prior to the participation. SPSS 20.0 was utilized and results were calculated with respect to percentages of responses and mean scores. Chi-square test was used to analyze the problems associated in effective implementation and integration of community pharmacy practices
\end{abstract} in Pakistan.

Results: Rate of response in the various cohort were in the order of $76 \%, 94 \%, 71 \%$ and $83 \%$ for local residents, pharmacist, physicians and pharmacy technicians respectively. Community pharmacy knowledge and beliefs mean scores were correspondingly found to be $1.971 .83,1.457 .44$, 2.842.10 and 2.385.54 for doctors, pharmacist, residents and technicians respectively.

Conclusion: A significant difference in the level of perception was observed amongst the professionals and local resident's cohort, which necessitates the effective and better execution of community residents counseling and more stringent implementation of health care facilities at the community level to improve the medication and health outcomes of related inhabitants.

Keywords: Community, Healthcare system, Pharmacist, Perception, Challenges

(C) 2016 The Authors. Published by Innovare Academic Sciences Pvt Ltd. This is an open access article under the CC BY license (http://creativecommons. org/licenses/by/4. 0/) DOI: http://dx.doi.org/10.22159/ijpps.2016v8i10.13169

\section{INTRODUCTION}

The profession of community pharmacy (CP) in recent days has gained significant attention worldwide due to its proven efficacy in drug-disease management and greater patient safety. Despite of this fact still in lowincome and developing countries including Pakistan, this specialized area of healthcare practice is in the infancy stage. One of the basic reasons is lack of legislations and regulations focusing the domain of community pharmacy in these countries [1,2]. Integration of community setup in primary healthcare facilities not only improves the course and outcome of treatment but also can maintain a relationship of confidence and belief with patients and customers. Furthermore patient education and counseling are a vital part of such activities to enhance strategic compliance and therapy adherence $[3,4]$. Main activities in which a community pharmacist can find their way to excel are direct care of the patients, formulation of extemporaneous preparations, responding to minor ailments and provision of drug information along with health promotional activities [5].

One of the most accessible heath care professionals to the common public are community pharmacists. Major roles of community pharmacist are the provision of medicines to the patient and public $[6,7]$. They participate in health promotion activities and maintain a collaborative approach with other health care providers. Globally, drugs and vaccines are found to be the most important tools for maintenance of heath but at the same time, they are associated with several adverse reactions with variable degrees depending on many patient and product related factors. The harmful effects of these medications proved to be even more worst in the case of developing countries where the accessibility towards all drugs is very easy, and all prescription and non-prescription drugs are achievable [8].
The success of community pharmacy professional is dependent on the strong relationship between a pharmacist and patient, the more collaborative approach practiced among them, the more compact community care system will evolve since pharmacist must have to be mature enough to give information, education and a complete services of pharmaceutical care to all patients $[9,10]$.

Few studies in a couple of years have been published in Pakistan linked to community pharmacy scope, major challenges, integration in healthcare setup and perception of people towards the efficacy of this system [11-13]. While the extent and eminence of such investigations were found with some degree of unevenness and disproportion related to their outcomes. Nonetheless, adequate information needs to be gathered from a large succession of different studies, to allow investigation of data regarding such imperative matters. The presented study has focused on important elements related to the integration of community setup in healthcare system at various levels. Findings of this investigation can be utilized as an educative rationale and source for local population, related health care professionals and other allied members to improve the implementation of such practices in order to get the better disease and drug outcome related to local settings.

\section{MATERIALS AND METHODS}

A qualitative, cross-sectional survey-based study was conducted to evaluate the integration of community setup in pharmaceutical care with respect to current challenges, awareness/perception of individuals from various walks of life, related facts and opportunities which are contextual to local settings in Karachi, Pakistan. A questionnaire was constructed using 15 close ended and 5 open-ended questions. The validity of questionnaire was validated 
using spearman coefficient of correlation and Cronbach's $\alpha$ value. For this purpose, a selected sample of survey form was filled initially by a specific group of respondents who were not included in this study.

Table 1: Demographic profiles of study participants

\begin{tabular}{|c|c|c|c|c|}
\hline Particulars & Local Residents & Pharmacists & Physicians & Technicians \\
\hline \multicolumn{5}{|l|}{ Gender } \\
\hline Male & $28(37 \%)$ & $42(45 \%)$ & $29(41 \%)$ & $74(89 \%)$ \\
\hline Female & $48(63 \%)$ & $52(55 \%)$ & $42(59 \%)$ & $9(11 \%)$ \\
\hline Total & 76 & 94 & 71 & 83 \\
\hline \multicolumn{5}{|c|}{ Years of Experience } \\
\hline Below one Year & - & $22(23 \%)$ & $19(27 \%)$ & $38(46 \%)$ \\
\hline Between 1-5 y & - & $42(45 \%)$ & $14(20 \%)$ & $24(29 \%)$ \\
\hline Between 6-10 y & - & $19(20 \%)$ & $17(24 \%)$ & $16(19 \%)$ \\
\hline Above $10 \mathrm{y}$ & - & $11(12 \%)$ & $21(20 \%)$ & $5(6 \%)$ \\
\hline
\end{tabular}

Table 2: Responses of respondents towards community pharmacy set-up and its efficacy

\begin{tabular}{|c|c|c|c|c|c|c|c|c|c|c|c|c|}
\hline \multirow[t]{2}{*}{ Questions } & \multicolumn{3}{|c|}{ Local residents } & \multicolumn{3}{|c|}{ Pharmacists } & \multicolumn{3}{|c|}{ Physicians } & \multicolumn{3}{|c|}{ Technicians } \\
\hline & Yes & No & Don't Know & Yes & No & Don't Know & Yes & No & Don't Know & Yes & No & Don't Know \\
\hline $\begin{array}{l}\text { a pharmacist } \\
\text { as an } \\
\text { essential and } \\
\text { effectual } \\
\text { member of } \\
\text { the health } \\
\text { care setup }\end{array}$ & $35(46 \%)$ & $25(33 \%)$ & $16(21 \%)$ & $78(83 \%)$ & $11(12 \%)$ & $5(5 \%)$ & $44(62 \%)$ & $25(35 \%)$ & $2(3 \%)$ & $26(31 \%)$ & $45(54 \%)$ & $12(14 \%)$ \\
\hline $\begin{array}{l}\text { the } \\
\text { community } \\
\text { pharmacist is } \\
\text { an important } \\
\text { element in } \\
\text { bridging the } \\
\text { gap between } \\
\text { the doctor } \\
\text { and the } \\
\text { patient }\end{array}$ & $29(38 \%)$ & $46(61 \%)$ & $1(1 \%)$ & $75(80 \%)$ & $9(10 \%)$ & $10(11 \%)$ & $38(54 \%)$ & $27(38 \%)$ & $6(8 \%)$ & $26(31 \%)$ & $45(54 \%)$ & $12(14 \%)$ \\
\hline $\begin{array}{l}\text { Effective set } \\
\text { ups of } \\
\text { community } \\
\text { pharmacy } \\
\text { can minimize } \\
\text { adverse drug } \\
\text { reactions or } \\
\text { medication } \\
\text { errors } \\
\text { committed } \\
\text { by healthcare } \\
\text { professionals }\end{array}$ & $22(29 \%)$ & $31(41 \%)$ & $23(30 \%)$ & $81(86 \%)$ & $9(10 \%)$ & $4(4 \%)$ & $37(52 \%)$ & $32(45 \%)$ & $2(3 \%)$ & $29(35 \%)$ & $35(42 \%)$ & $19(23 \%)$ \\
\hline $\begin{array}{l}\text { a community } \\
\text { pharmacist } \\
\text { can improve } \\
\text { the course of } \\
\text { drug therapy } \\
\text { and educate } \\
\text { patient about } \\
\text { drugs more } \\
\text { appropriately } \\
\text { than a non- } \\
\text { community } \\
\text { pharmacist }\end{array}$ & $16(21 \%)$ & $45(59 \%)$ & $15(20 \%)$ & $87(93 \%)$ & $0(0 \%)$ & $7(7 \%)$ & $48(68 \%)$ & $20(28 \%)$ & $3(4 \%)$ & $29(35 \%)$ & $35(42 \%)$ & $19(23 \%)$ \\
\hline $\begin{array}{l}\text { Pharmacist } \\
\text { in } \\
\text { community } \\
\text { does better } \\
\text { patient } \\
\text { educate } \\
\text { about drugs } \\
\text { more } \\
\text { appropriately } \\
\text { than a non- } \\
\text { community } \\
\text { pharmacist }\end{array}$ & $28(37 \%)$ & $31(41 \%)$ & $17(22 \%)$ & $81(86 \%)$ & $3(3 \%)$ & $10(11 \%)$ & $54(76 \%)$ & $17(24 \%)$ & $0(0 \%)$ & $23(28 \%)$ & $27(33 \%)$ & $33(40 \%)$ \\
\hline $\begin{array}{l}\text { consultation } \\
\text { at } \\
\text { community } \\
\text { pharmacy } \\
\text { can improve } \\
\text { patient } \\
\text { compliance } \\
\text { and minimize } \\
\text { drug } \\
\text { interactions } \\
\text { establishing }\end{array}$ & $39(51 \%)$ & $23(30 \%)$ & $13(17 \%)$ & $79(84 \%)$ & $2(2 \%)$ & $13(14 \%)$ & $44(62 \%)$ & $26(37 \%)$ & $1(1 \%)$ & $29(35 \%)$ & $28(34 \%)$ & $21(25 \%)$ \\
\hline
\end{tabular}




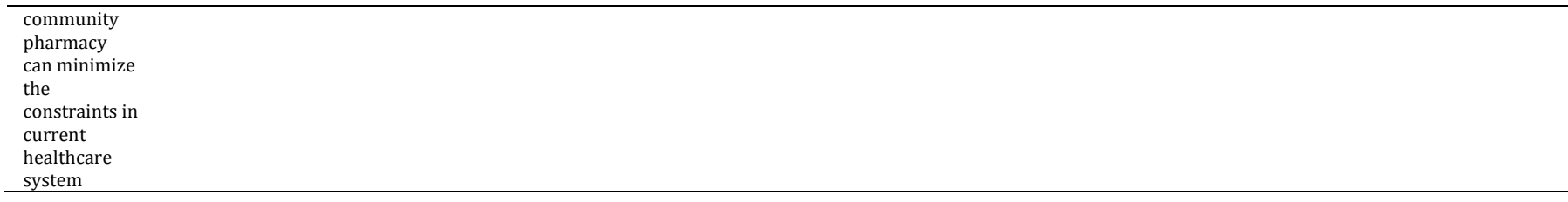

Values of these parameters were found $\alpha=0.916$ and $p=0.941$ have shown the acceptable reliability and consistency of questionnaire. Local residents, pharmacist, medical practitioners, and pharmacy technicians were selected as study participants. Informed consents of all respondents were obtained prior to the participation.

This study was conducted between May-November 2015. Demographic details of participants are summarized in table 1 with respect to age, gender and level of experience of professionals. Perception of study respondents was analyzed using likert scale format with bipolar statements and mean scores for their levels of beliefs were calculated. Various factors and challenges for establishing the community pharmacy in Pakistan were also sought out during the survey. Results were statistically analyzed using SPSS 20.0.

\begin{abstract}
RESULTS
Table 1 summarized all relevant demographic profiles of respondents who participated in the study course. Local residents $(n=76)$, pharmacists $(n=94)$, physicians $(n=71)$ and technicians $(n=$ 83) were included and responded the questionnaire. Considering the particulars, the majority of technicians (89\%) and pharmacist (49\%) were male and a large the number of female participants was more likely to participate in all categories except as technicians.

Approximately $20 \%$ physicians and $12 \%$ pharmacist had more than $10 \mathrm{y}$ of experience in their field comparative to $6 \%$ of technicians. However, $45 \%$ pharmacist and $46 \%$ technicians found to have 1-5 y and less than $1 \mathrm{y}$ of experience respectively.
\end{abstract}

Table 3: Major challenges for integration of community setup in health care system

\begin{tabular}{|c|c|c|c|c|}
\hline Factors & Local residents $(n=76)$ & $\begin{array}{l}\text { Pharmacist } \\
(n=94)\end{array}$ & $\begin{array}{l}\text { Physicians } \\
(n=71)\end{array}$ & $\begin{array}{l}\text { Technicians/others } \\
(n=83)\end{array}$ \\
\hline Current constraints in Healthcare system & $22(28.9 \%)$ & $63(67.2 \%)$ & $49(69.01 \%)$ & $47(56.62 \%)$ \\
\hline Lack of awareness & $43(56.5 \%)$ & $16(17 \%)$ & $37(52.11 \%)$ & $13(15.66 \%)$ \\
\hline Level of education in public & $15(19.7 \%)$ & $12(12.7 \%)$ & $26(36.61 \%)$ & $17(20.48 \%)$ \\
\hline Lack of Skilled Professionals/training & $49(64.4 \%)$ & $27(28.7 \%)$ & $35(49.29 \%)$ & $14(16.86 \%)$ \\
\hline Lack of patient demand & $26(34.2 \%)$ & $25(26.4 \%)$ & $17(23.94 \%)$ & $46(55.42 \%)$ \\
\hline Other can perform same responsibilities effectively & $19(25 \%)$ & $00(0 \%)$ & $08(11.26 \%)$ & $39(46.98 \%)$ \\
\hline Professionals demands high salaries & $56(73.6 \%)$ & $43(45.7 \%)$ & $36(50.70 \%)$ & $19(22.89 \%)$ \\
\hline Others & $12(15.7 \%)$ & $9(9.5 \%)$ & $15(21.12 \%)$ & $03(3.61 \%)$ \\
\hline
\end{tabular}

Major challenges for establishing the community pharmacy practices in Pakistan, when asked from study respondents they came up with several commonalities in their opinion, with some differences as well. Their responses are summarized in table 3 .

Table 4: Statistical summary of key problems associated with assimilation of community structure in health care set up (Chi-Square)

\begin{tabular}{|c|c|c|c|c|c|}
\hline Factors & Approach & Value & Asymp. sig. (2-sided) & Exact sig. (2-sided) & Exact sig. (1-sided) \\
\hline Current constraints in & Pearson Chi-Square & $32.077^{a}$ & 0.000 & 0.000 & \\
\hline \multirow[t]{2}{*}{ Healthcare system(HCS) } & Likelihood proportion & 32.543 & 0.000 & 0.000 & \\
\hline & Linear-by-Linear correlation & $9.775^{\mathrm{b}}$ & 0.002 & 0.002 & 0.001 \\
\hline \multirow[t]{3}{*}{ Lack of awareness } & Pearson Chi-Square & $52.412^{\mathrm{a}}$ & 0.000 & 0.000 & \\
\hline & Likelihood proportion & 53.675 & 0.000 & 0.000 & \\
\hline & Linear-by-Linear correlation & $13.063^{\mathrm{b}}$ & 0.000 & 0.000 & 0.000 \\
\hline \multirow[t]{3}{*}{ Level of education in public } & Pearson Chi-Square & $14.005^{\mathrm{a}}$ & 0.003 & 0.003 & \\
\hline & Likelihood proportion & 13.420 & 0.004 & 0.004 & \\
\hline & Linear-by-Linear correlation & $1.540^{\mathrm{b}}$ & 0.215 & 0.225 & 0.119 \\
\hline Lack of Skilled & Pearson Chi-Square & $45.312^{\mathrm{a}}$ & 0.000 & 0.000 & \\
\hline \multirow[t]{2}{*}{ Professionals/training } & Likelihood proportion & 46.735 & 0.000 & 0.000 & \\
\hline & Linear-by-Linear correlation & $24.410^{\mathrm{b}}$ & 0.000 & 0.000 & 0.000 \\
\hline Lack of patient demand & Pearson Chi-Square & $21.911^{\mathrm{a}}$ & 0.000 & 0.000 & \\
\hline \multirow{2}{*}{ (patient awareness) } & Likelihood proportion & 21.501 & 0.000 & 0.000 & \\
\hline & Linear-by-Linear correlation & $7.608^{\mathrm{b}}$ & 0.006 & 0.006 & 0.003 \\
\hline Other can perform same & Pearson Chi-Square & $64.930^{\mathrm{a}}$ & 0.000 & 0.000 & \\
\hline \multirow[t]{2}{*}{ responsibilities effectively } & Likelihood proportion & 77.330 & 0.000 & 0.000 & \\
\hline & Linear-by-Linear correlation & $18.020^{\mathrm{b}}$ & 0.000 & 0.000 & 0.000 \\
\hline \multirow{3}{*}{$\begin{array}{l}\text { Professionals demands high } \\
\text { salaries }\end{array}$} & Pearson Chi-Square & $12.650^{\mathrm{a}}$ & 0.005 & 0.005 & \\
\hline & Likelihood proportion & 13.579 & 0.004 & 0.004 & \\
\hline & Linear-by-Linear correlation & $2.542^{\mathrm{b}}$ & 0.111 & 0.125 & 0.064 \\
\hline \multirow[t]{3}{*}{ Others } & Pearson Chi-Square & $41.456^{\mathrm{a}}$ & 0.000 & 0.000 & \\
\hline & Likelihood proportion & 43.422 & 0.000 & 0.000 & \\
\hline & Linear-by-Linear correlation & $34.315^{\mathrm{b}}$ & 0.000 & 0.000 & 0.000 \\
\hline
\end{tabular}

Important problems associated in effective implementation of community practices in Pakistan are statistically analyzed in view of study respondents present in various cohorts and presented in table 4. 


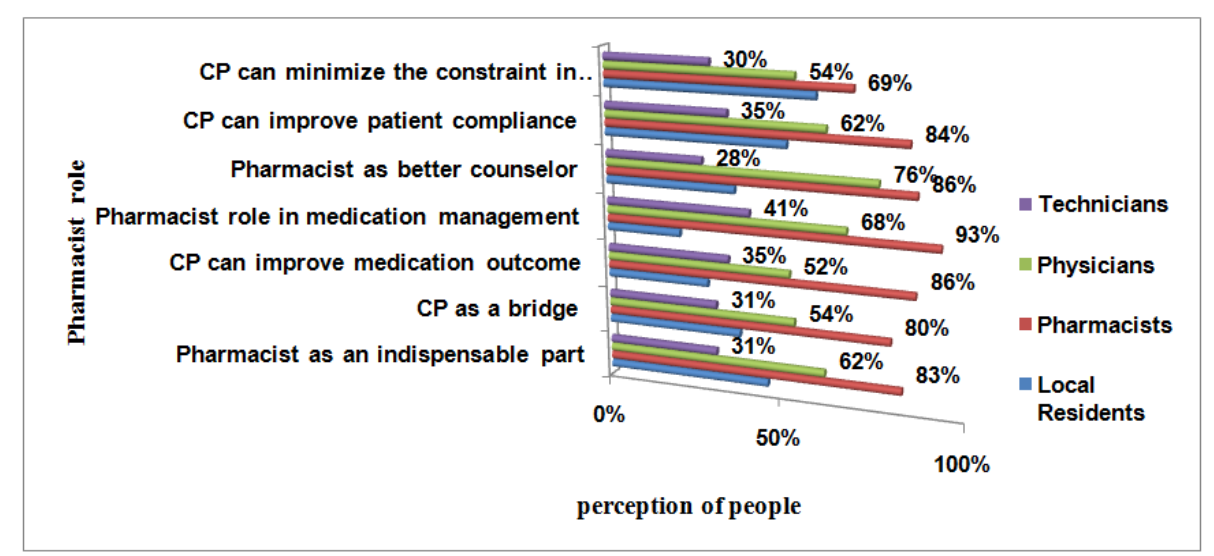

Fig. 1: Perception of different cohorts towards community pharmacy and role of pharmacist [CP = Community pharmacist $]$

\section{DISCUSSION}

Worldwide, Pharmacy management and associated academic disciplines have built up pharmaceutical responsibilities and established the regular plans for patient concern. Generally, it has been thought that community setup extensively contributed to the fundamental care and social wellbeing, particularly in advanced states. Maltese and Portuguese acknowledge the health care services provided by the community pharmacists within society $[13,14]$. The Saudi patients revealed superior contentment, awareness, and gratitude of the pharmacists' responsibility in the health care platform [15]. Community pharmacists (CP) are uniquely placed to provide support and advice to the general public compared with other health care specialists. The present study recognizes the facts governed regarding the inhabitant's opinion, perspectives, and satisfaction with pharmacists who act as health care supporter inside the context of community pharmacy in Karachi, Pakistan.

Opinion (perception) of various cohorts were determined by using the selective design of likert scale with the bipolar arrangement and mean scores were tabulated to rank their attitudes (beliefs) toward community pharmacy as an obligatory part of healthcare setup. Results were found in order of 1.971.83, 1.457.44, 2.842.10 and 2.385.54 for doctors, pharmacist, residents and technicians respectively. A significant difference in the level of perception was observed amongst the professionals and local resident's cohort, which necessitates the effective and better execution of community residents counseling and more stringent implementation of health care facilities at the community level to improve the medication and health outcomes of related inhabitants.

The advancement of the professional and educational background of community pharmacy clearly signifies and dedicated the pharmacist's performance in patient care activities each day. Community pharmacists are the active members of patient care team who assess the status of patient's health problems and determine that prescribed medications optimally meet the standard goal of care or not. They involve in all over the process of care including education and counseling about appropriate product selection, ensure safe route of administration, dosage, and storage, identification and fend off medication failure along with adverse drug reactions [16]. Community pharmacists are routinely engaged in patient education and counseling whenever to involve in dispensing medication or handling prescriptions or provide both health care facilities at the pharmacy counter and as a separate service [17].

Pharmacists contributed strongly to obtain optimistic outcomes of medication therapy by means of consistent educational approach and counseling strategy for patients on important steps in order to improve and maintain health conditions as well as to prepare monitoring plans [18]. A systematic review finding indicate that pharmacists led counseling improve clinical outcomes, quality of life, drug and disease knowledge, patients' satisfaction with service, and economic outcomes [19]. Table 2 illustrated the responses of respondents towards community pharmacy system and its effectiveness. Approximately (83\%) of pharmacists, (62\%) physicians and $(46 \%)$ of local residents were completely satisfied with the effective role of community pharmacist in health care system. Community pharmacists are recognized as the health professionals who are most accessible to the public. Similarly, (80\%) of pharmacists and (54\%) physicians and (38\%) local residents having an awareness that community pharmacist is an important element in bridging the gap between the doctor and the patient except for (31\%) technicians. Pharmacists take part to ensure the appropriateness, effectiveness and safety of patient's medication use. Having sufficient scientific knowledge about medicines and disease history are the pharmacists' clinical tools to overcome the medication-related problems or avoidance from adverse drug reactions. Moreover, (86\%) pharmacists in association of $(52 \%)$ physicians and (35\%) technicians responses to have sufficient knowledge about the responsibility of community pharmacist in minimizing adverse drug reactions or medication errors committed by healthcare professionals. Health awareness campaigns carried out in several developed countries to raise the public responses about increasing role of the pharmacist in provisions of health care service given to the patient in the community settings. Patient counseling encourage the patient to identify any problem they perceive with medicines. Community pharmacists actively engaged and use their counseling skills with patients. The result of the survey showed, in comparison to (93\%) pharmacists, $(68 \%)$ physicians and $(35 \%)$ technicians, very few local residents $(21 \%)$ agreed that community pharmacist facilitates patient counseling or involve in health educational programs. They may also take part in the education of local community groups in health promotion, and in campaigns on disease prevention. A number of factors involve in poor patient compliance because of expensive treatment, long-term disease condition, increased toxicity, therapeutic failure and confusion to take medicines as directed by the physician. All these reviews effectively recognized the roles of the pharmacist in the current practice to recover patients' compliance and reduce drug interactions. Therefore, the information about the compliance of the previously dispensed medication is an important feedback for the pharmacist. The majority of pharmacists, physicians, local residents and technicians agreed by the significant role of pharmacists in developing doctor-patients relationships [table 2].

Drugs with a narrow therapeutic range or low therapeutic index are more likely to be the objects for serious drug interactions. The pharmacist, along with the prescriber has a duty to ensure that patients are aware of the risk of side effects and a suitable course of action should they occur. In addition to multiple responsibilities of community pharmacists, their substantial contribution also noticed in prevention, detection, monitoring and reporting ADRs (account the considerable proportion of hospital admission) at the community level [20]. Secondly, community pharmacies are fully managed and run by qualified pharmacists to promote safer use of medicines and help in reducing potential drug related problems. They have an opportunity to improve the healthcare of the 
population, particularly in areas with lack of resources to visit hospital. However, a large number of obstacles still present such as lack of appropriate education/ knowledge, the guidance of pharmacists, the uncertainty of existing legislation, and insufficient acknowledgment of pharmacy as a profession by the other health care experts [21]. Barriers between general physicians (GPs) and community pharmacists must be identified and conquer whenever inter-professional association among the two specialties is to be completely realized [22]. Exploring pharmacists' perceptions on their role within the community pharmacies is a challenging task because pharmacists face many constraints in many countries. Most of the physicians $(69.01 \%)$, pharmacists $(67.2 \%)$ and technicians (56.62\%) ranked current constraints as a significant issue in addition to insufficient awareness reported by local residents and physician about health care system while developing community set up. Physicians and local residents highlighted the lack of professional skills and training programs and demanding high salaries with the establishment of community pharmacy [table 3]. In addition, a large number of pharmacists (69\%) supported the establishment of community pharmacy and the role of community pharmacist (CP) in reducing the constraint in health care system. With the growing emphasis in healthcare systems on securing value from medicines, it is all the more imperative to make sure these medicines are taken as directed.

Approximately, (84\%) pharmacists and (62\%) physicians focused the improved patient compliance facilitated by community pharmacist by means of patient education and motivation or developing a strong patient-pharmacists relationship to understand patient's needs and increase the level of compliance. In addition, (86\%) pharmacists in the association of (76\%) physicians considered $\mathrm{CP}$ as best drug expert or drug custodian for health care management within society. It has been suggested that counseling by CP could led to better compliance and hence less therapeutic failure. In community pharmacy, patients counseling should be as an integral part of the dispensing of a prescription. A positive change was noticed with pharmacists (82\%) and physicians (52\%) to analyze the effect of enhanced therapeutic monitoring by $\mathrm{CP}$ on clinical outcomes [fig. 1]. Integrated health systems are considered at least in part a solution to the challenge of sustainability. Previously scientific researchers proposed that a variety of interprofessional complexities stay between community pharmacists and GPs which impede the coordination of community pharmacists into the primary health management [23]. It is need of time to generate a system for prescription verification and standard prescribing protocols. Instructions and guidelines for the pharmacist and dispensers should be formulated for each community which may lead to decrease the chances of inappropriate medication dispensing and adverse events [24]. The participation of community/clinical pharmacists in different health care setups may result in better and efficient medication utilization with optimal approach [25-28]. Pharmacy practice models in established regions differ significantly from one country to another. Some of the major issues identified as an acute shortage of qualified pharmacists, staff shortage and service demand [29]. Continuous professional development modules must be designed to develop and validate to assess the impact of a training program on knowledge and skills of community pharmacists [30].

\section{CONCLUSION}

In conclusion, existing study judiciously demonstrates the responsiveness among numerous cohorts with acceptable acquaintance and perception. A customary accord towards the stipulation of community setup was observed during the study. Therefore, it is strappingly suggested to amplify and illuminate the integrity of pharmaceutical practices at the community level. These activities may require continuous education and awareness programs in collaboration with various stakeholders such as healthcare providers, government personnels and pharmacy professionals. Such practices not only provide the optimal care and effective drug monitoring in respective communities but also work as the bridge between the patient, physician, and pharmacist. Hence it is need of time to set priority and to formulate efficient tools for successful integration of community practices to improve patient's safety and therapeutic outcomes.

\section{CONFLICT OF INTERESTS}

Declared none

\section{REFERENCES}

1. Khan T. Challenges to pharmacy and pharmacy practice in Pakistan. Med J Aust 2011;4:230-5.

2. Alam MT. Short note: concept and scope of community pharmacy. Pak J Pharm Sci 1995;8:87-90.

3. Anand S, Barnighausen T. Human resources, and health outcomes: cross-country econometric study. Lancet 2004; 364:1558-60.

4. Wirth F, Tabone F, Azzopardi LM, Gauci M, Zarb-Adami M, Serracino-Inglott A. Consumer perception of the community pharmacist and community pharmacy services in Malta. J Pharm Health Services Res 2010;1:189-94.

5. Rabbani F, Cheema FH, Talati N, Siddiqui S, Syed S, Bashir S, et al. Behind the counter: pharmacies and dispensing patterns of pharmacy attendants in Karachi. J Pak Med Assoc 2001;51:149-53.

6. Smith F. Community pharmacy in Ghana: enhancing the contribution to primary health care. Health Policy Planning 2004;19:234-41.

7. Greenhalgh T. Drug prescription and self-medication in India: an exploratory survey. Soc Sci Med 1987;25:307-18.

8. Butt ZA, Gilani AH, Nanan D, Sheikh AL, White F. Quality of pharmacies in Pakistan: a cross-sectional survey. Int J Qual Health Care 2005;17:307-13.

9. Worley MM, Schommer JC, Brown LM, Hadsall RS, Ranelli PL, Stratton TP, et al. Pharmacists and patients roles in the pharmacist-patient relationship: are pharmacists and patients reading from the same relationship script? Res Soc Administrative Pharm 2007;3:47-69.

10. Syhakhang L, Stenson B, Wahlstrom R, Tomson G. The quality of public and private pharmacy practices: a cross-sectional study in the Savannakhet province. Eur J Clin Pharm 2001;57:221-7.

11. Amir M. Assessing the acceptability of community pharmacy based pharmaceutical care services in Karachi. Innovation Pharm 2011;2:1-5.

12. Islam A. Health sector reform in Pakistan: Why is it is needed? J Pak Med Assoc 2002;52:95-100.

13. Azhar S, Hassali MA, Ibrahim MI, Ahmad M, Masood I, Shafie AA. The role of pharmacists in developing countries: the current scenario in Pakistan. Hum Resour Health 2009;7:54.

14. Cavaco AM, Dias JP, Bates IP. Consumers' perceptions of community pharmacy in portugal: a exploratory qualitative study. Pharm World Sci 2005;27:54-60.

15. Mohamed NAA. Patients' perception, views, and satisfaction with pharmacists' role as health care provider in a community pharmacy setting at Riyadh, Saudi Arabia. Saudi Pharm J 2012;20:323-30.

16. Hammerlein A, Griese N, Schulz M. Survey of drug-related problems identified by community pharmacies. Ann Pharmacother 2007;41:1825-32.

17. American Society of Health-System Pharmacists ASHP guidelines on pharmacist-conducted patient education and counseling. Am J Health Syst Pharm 1997;54:431-4.

18. Yamada K. Pharmacist-managed clinics for patient education and counseling in Japan: current status and future perspectives. J Pharm Health Care Sci 2015;1:2.

19. Okumura LM, Rotta I, Correr CJ. Assessment of pharmacist-led patient counseling in randomized controlled trials: a systematic review. Int J Clin Pharm 2014;36:882-91.

20. Palanisamy S, Arul Kumaran KS, Rajasekaran A. A study on assessment, monitoring, documentation and reporting of adverse drug reactions at a multi-specialty ertiary care teaching hospital in South India. Int J PharmTech Res 2009;4:1519-22. 
21. Basak SC, Van MJW, Sathyanarayana D. The changing roles of pharmacists in community pharmacies: perception of reality in India. Pharm World Sci 2009;31 Suppl 6:612-8.

22. Carmel MH, Siobhan M. Perceived inter-professional barriers between community pharmacists and general practitioners: a qualitative assessment. Br J General Practice 2003;53:600-6.

23. Bradley F, Elvey R, Ashcroft DM, Hassell K, Kendall J, Sibbald B, et al. The challenge of integrating community pharmacists into the primary health care team: a case study of local pharmaceutical services (LPS) pilots and interprofessional collaboration. J Interprofessional Care 2008;22:387-98.

24. Shoaib MA, Shafiq M, Nadeem I, Rashid H, Abdul M, Imran MQ. Assessment of prescribing practices of private GP's in Islamabad. Int J Curr Pharm Res 2013;5:49-53.

25. Neethu FU, Juno JJ, Raghav S, Shastry CS, Ramesh A. Significant role of clinical pharmacists in the assessment of inappropriate medications prescribed to the elderly patients in a university teaching hospital. Asian J Pharm Clin Res 2015;8:109-12.

26. Ravinandan AP, Achutha V, Vikram K, Uttangi S, Uttangi L. Study of Knowledge, Attitude and practice of pharmacist towards adverse drug reaction reporting in dawangere city. Asian J Pharm Clin Res 2015;8:262-5.
27. Sushikumar PL. Implementation and evaluation of health screening services to diabetic and hypertensive patients in a selected community pharmacy at Belgaum city. Asian J Pharm Clin Res 2015;8:305-15.

28. Sainul A, Kalaiselvan V, Pradeep M. Assessment of the prevalence of potential drug-drug interactions in a medical intensive care unit of a tertiary care hospital in India. Asian J Pharm Clin Res 2015;8:125-30.

29. Fleury MJ. Integrated service networks: the quebec case. Health Ser Manag Res 2006;19:153-65.

30. Adepu R, Shariff A. Development, Validation and implementation of continuous professional development programs for community pharmacists. Indian J Pharm Sci 2010;72:557-63.

\section{How to cite this article}

- Huma Ali, Farya Zafar, Shazia Alam, Neelam Mallick, Hina Hasnain, Ghazala Raza Naqvi, Zeb-UN-Nisa, Anum Tariq, Aslam Shah. Integration of community setup in pharmaceutical care: current challenges, perception, facts and opportunities in Pakistan. Int J Pharm Pharm Sci 2016; 8(10):138-143. 